\title{
GEOMETRICAL AND STATISTICAL METHODS OF ANALYSIS OF STAR CONFIGURATIONS. DATING PTOLEMY'S ALMAGEST
}

CRC Press, Boca Raton, 1993.

\author{
ANATOLY T. FOMENKO \\ Department of Mathematics and Mechanics \\ Moscow State University \\ 119899 Moscow, Russia \\ anatoly@fomenko.mian.su \\ VLADIMIR V. KALASHNIKOV \\ Institute of Systems Studies, 9, Prospect 60 let \\ Oktyabrya, 117312 Moscow, Russia \\ mconeau@glas.apc.org \\ Fax: (095) 938-2209 \\ and \\ G.V. NOSOVSKY \\ Department of Mathematics and Mechanics \\ Moscow State University \\ 119899 Moscow, Russia.
}

The book presents an unusual application of statistical and geometrical methods to dating ancient astronomical documents. An exciting result of the book consists of placing the date of Ptolemy's principal work "Almagest" in the Middle Ages instead of its traditional date (second century A.D.). The main body of the book contains statistical analysis of Ptolemy's star catalogue (systematic errors, accuracy, inclination of the ecliptic, dating the star catalogue). The elaborated method is tested on some medieval star catalogs (T. Brahe, Ulugh Beg, Hevelius, Al Sufi). In addition, the results are confirmed by other dating based on coverings of stars and lunar eclipses. The book contains necessary notions and concepts of astronomy and history and an addendum discussing historical problems and hypotheses related to dating the Almagest. 


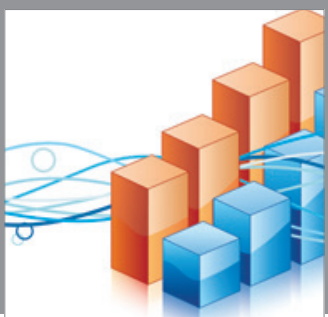

Advances in

Operations Research

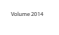

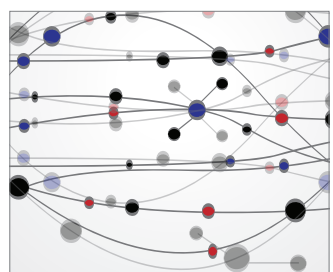

\section{The Scientific} World Journal
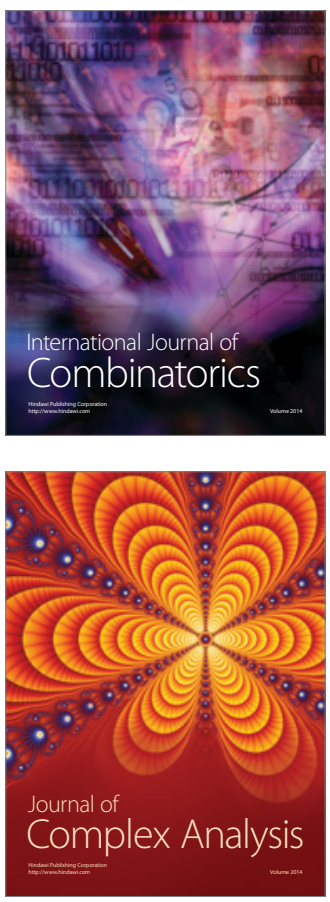

International Journal of

Mathematics and

Mathematical

Sciences
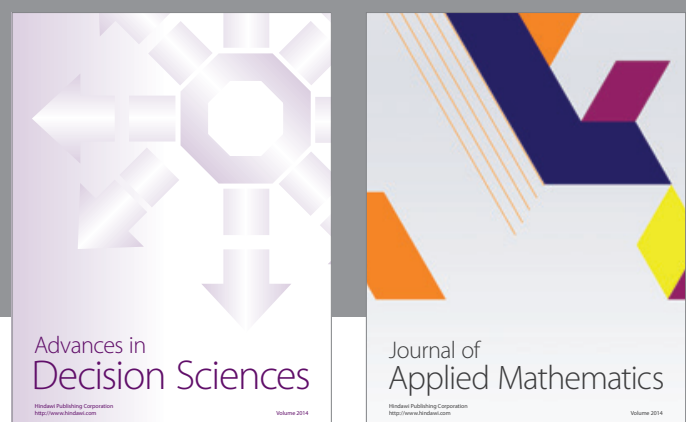

Journal of

Applied Mathematics
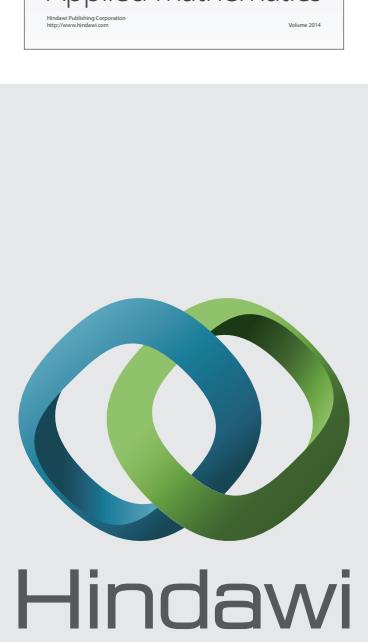

Submit your manuscripts at http://www.hindawi.com
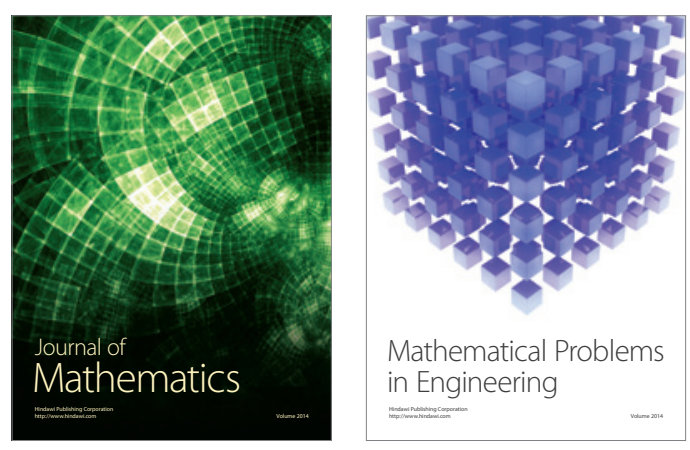

Mathematical Problems in Engineering
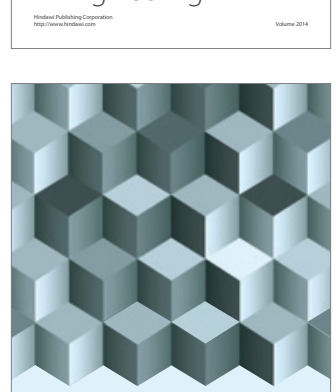

Journal of

Function Spaces
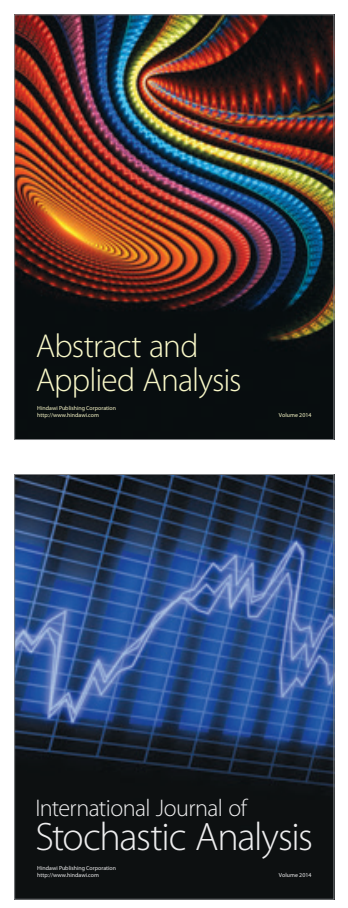

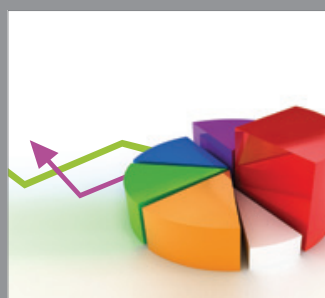

ournal of

Probability and Statistics

Promensencen
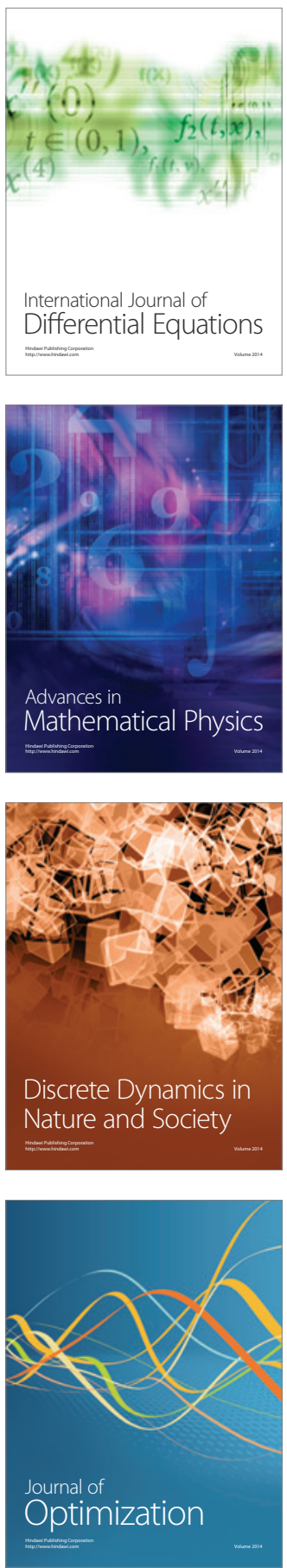